\title{
Pueblos indígenas y enseñanza de la historia en perspectiva intercultural en escuelas secundarias del sur bonaerense (Argentina)
}

\section{Hernán Perrière}

Dpto. Humanidades. Universidad Nacional del Sur (UNS). Bahía Blanca, Argentina. Becario posdoctoral del CONICET.

(iD) ORCID: https://orcid.org/oooo-0oo3-3984-1379

Correo electrónico: hernanperriere@hotmail.com
Recibido:

9 de abril de 2021

Aceptado:

17 de agosto de 2021

doi: 10.34096/runa.v43i1.10038

\section{Resumen}

En este artículo abordo la enseñanza de la historia en tres escuelas secundarias de la ciudad de Bahía Blanca desde una perspectiva etnográfica, con la intención de problematizar los supuestos nacionalizadores presentes en los discursos escolares tendientes a invisibilizar a los pueblos indígenas. Esto permite analizar cómo se reactualizan las visiones de nacionalidad que históricamente han justificado el genocidio indígena y estudiar las tensiones entre la continuidad del mandato nacionalista dominante y la incorporación de la perspectiva intercultural según la Ley de Educación Nacional (2006). Presento tres planos de análisis: el de la larga duración, que marca una persistencia en el tratamiento de la nacionalidad desde mediados del siglo XIX; el de la continuidad relativa, que incorpora el análisis de la interculturalidad en las normativas escolares y los límites de su aplicación en la provincia de Buenos Aires; y finalmente, el estudio de la problemática indígena y su tratamiento en la cotidianeidad escolar.

Indigenous peoples and teaching of history from an intercultural perspective in as high school in southern Buenos Aires (Argentina)

\begin{abstract}
In this article I approach the teaching of the History in three high schools in Bahía Blanca city from an ethnographic perspective, with the intention of problematizing the nationalizing assumptions present in school discourses that tend to make indigenous peoples invisible. This allows to analyze how
\end{abstract}

Palabras clave

Pueblos indígenas; Enseñanza de la historia; Interculturalidad: Escuela secundaria; Sur bonaerens

Key wards

Indigenous peoples; History teaching; Interculturality; High school; South of Buenos Aires 
the visions of nationality historically have justified the indigenous genocide and to study the tensions between the continuity of the dominant nationalist mandate and the incorporation of the intercultural perspective according to the National Education Law (2006). I present three analysis plans: the long duration that marks a continuity in the treatment of nationality since the midnineteenth century. That the relative continuity that incorporates the intercultural analysis in the school normatives, and the limits of its application in the Buenos Aires province. Finally, the study of indigenous problems and its treatment in everyday school life.

\section{Povos indígenas e o ensino de história desde uma perspecti- va intercultural no escola secundária do sul de Buenos Aires (Argentina)}

\section{Resumo}

Palavras-chave

Povos indígenas; Ensino de História; Interculturalidade; Escola Secundária; Sul bonaerense
Neste artigo, eu abordo o ensino de História em três escolas secundárias a cidade da Bahía Blanca a partir de uma perspectiva etnográfica, com o intuito de problematizar os supostos nacionalizadores presentes nos discursos escolares que tendem a invisibilizar os povos indígenas. Isso permite analisar como revisar as visões de nacionalidade que historicamente justificaram o genocídio indígena e estudar as tensões entre a continuidade do mandato nacionalista dominante e a incorporação de uma perspectiva intercultural de acordo com a Lei Nacional de Educação (2006). Eu apresento três planos de análise: a longa duração que marca a continuidade no tratamento da nacionalidade desde o século XIX. O da continuidade relativa que incorpora a análise da interculturalidade nos regulamentos escolares e os limites de sua aplicação na província de Buenos Aires. Por fim, o estudo da problemática indígena e seu tratamento no cotidiano escolar.

\section{Introducción}

En el momento de escribir este artículo, los conflictos indígenas volvían a ocupar la prensa en la Argentina y a instalar nuevamente la discusión sobre la problemática de la tierra en Villa Mascardi (Río Negro, Patagonia Argentina). En ese contexto, un legislador denunció al Estado nacional afirmando que la toma de tierras del pueblo mapuche no sería un delito sino la expropiación de una parte de la nación a otra (Infobae, 31 de marzo, 2021). En el transcurso del mismo conflicto, un editorial del diario La Nación aseveró que el objetivo final de los grupos mapuches es "crear un Estado dentro de un Estado" y que "todas las usurpaciones comparten una misma motivación: "crear en territorio argentino una nación mapuche" (La Nación, 6 de marzo, 2021). En la misma provincia, en el año 2016, el entonces ministro de Educación y Deportes, Esteban Bullrich, retomó, en un acto público de inauguración de una sede universitaria, la metáfora de la "Conquista al desierto" pero esta vez sin espadas, sino con educación (Diez et al., 2016). 
En la Argentina, los discursos reaccionarios emergen cuando los pueblos indígenas presentan sus demandas en la esfera pública. Como expone Mariano Nagy (2018), con su sola presencia golpean la versión patriótica y festiva de nuestro país. De este modo, se reactualizan discusiones históricas y emergen sentidos y prácticas racistas en las que cobran vigencia ideas sobre la identidad nacional, la función del Estado y el papel de la educación.

En este artículo recupero y problematizo los supuestos nacionalizadores presentes en los discursos escolares, tendientes a invisibilizar a los pueblos indígenas considerándolos como parte del pasado porque fueron "eliminados" o "asimilados" por el bien de "la nación" y la producción capitalista durante el proceso de conformación del Estado argentino. Cuestionar estos supuestos permite analizar la manera en que se reactualizan las visiones de nacionalidad que históricamente han justificado el genocidio indígena (Lenton, 2014), con las consecuentes perspectivas acerca de una ciudadanía desindigenizada (Navarro Floria, 2002; Lenton, 2010; Delrio 2010, 2011, 2015) focalizando en la enseñanza de la historia en la escuela secundaria desde una mirada que excede lo estrictamente didáctico.

De este modo dialogo con los supuestos teóricos y de sentido común que afirman que la finalidad de la enseñanza de la historia es transmitir centralmente aquellos aspectos vinculados a la nacionalidad. Considero que esta función que se le asigna a dicha disciplina en la escuela secundaria no permite visualizar las tensiones que se expresan entre la continuidad de un mandato nacionalizante dominante y la incorporación de la perspectiva intercultural que se instala en la Argentina en los marcos normativos nacionales desde la sanción de la Ley de Educación Nacional (LEN) desde el año 2006. Sin embargo, en la provincia de Buenos Aires, el tratamiento de la interculturalidad contemplado en la ley de educación provincial y en otras normativas presenta contradicciones en su aplicación, y en el diseño curricular de tercer año de la escuela secundaria se invisibiliza a los pueblos originarios y los procesos de disputas territoriales en la conformación del Estado argentino.

Retomando algunas de las ideas mencionadas, en el sur de la provincia de Buenos Aires, las elites políticas locales articularon un discurso muy eficaz que, basándose en algunas investigaciones de la Universidad Nacional del Sur (UNS), estructura una narración que establece que la ciudad de Bahía Blanca fue fundada dos veces durante el siglo XIX (Cernadas, Bracamonte y Agesta, 2016; Heredia Chaz, 2018). Considero que estos dos hitos fundacionales remiten a procesos históricos distintos. La fundación de la Fortaleza Protectora Argentina refiere a una campaña militar que dio origen a la ciudad de Bahía Blanca en 1828, mientras que la fundación del puerto de Ingeniero White y la llegada del ferrocarril en 1884 aluden a la instalación de la infraestructura de comercio y transporte como punto de partida para el crecimiento urbano en las últimas décadas del siglo XIX. ${ }^{1}$ La idea rectora de este relato que unifica las "dos fundaciones" afirma la mirada de los grupos dominantes: una imagen de "progreso" frente al "desierto" que se articula bajo el binomio "civilizaciónbarbarie". De esta manera, se invisibiliza un periodo conflictivo de relaciones interétnicas y una disputa por el control de un área de frontera (malones, campañas militares, relaciones comerciales, entre otras) que excedió el control estatal por más de medio siglo (Villar, Jiménez y Ratto, 1998; Villar y Jiménez, 2004; Alioto, 2011).

Este artículo se enmarca en el campo de la antropología y educación y en las investigaciones educativas etnográficas que problematizan las discusiones
1. Según el Plan Estratégico de Bahía Blanca (1998), fue el historiador Hernán Silva quién acuñó dicho concepto en 1979, en ocasión del Congreso Nacional de Historia sobre la Conquista del Desierto, al plantear que a partir de los primeros años de la década de 1880 , la ciudad experimentó una "Refundación, no formal [...] el nacimiento de una Segunda Bahía Blanca" (Heredia Chaz, 2018, p. 23). 
sobre la interculturalidad en la Argentina. Metodológicamente, el trabajo de campo etnográfico realizado en escuelas secundarias del sur bonaerense (20142018), en el marco de una investigación doctoral, permitió distinguir que en el tratamiento de los temas históricos hay un cuestionamiento a la centralidad y dominio del Estado en el siglo XIX en el área de estudio. Asimismo, en las clases observadas y en las entrevistas realizadas, surgieron otros aspectos temáticos referidos a las problemáticas históricas y actuales que vivencian los pueblos indígenas, especialmente las vinculadas al territorio.

Para la estructura de este artículo realizo una relectura de las investigaciones realizadas por la antropóloga Elsie Rockwell (2000) para el análisis de las culturas escolares y la diversidad escolar, aunque ella focalizó en las prácticas de escritura. En primer lugar, retomo lo que ella llama el plano de la "larga duración"; me refiero acá al tratamiento constitutivo de las ideas sobre la nación, la disciplina Historia, la enseñanza de la historia y la trasmisión de la nacionalidad. Luego analizo el plano de la "continuidad relativa", haciendo alusión a la superposición de los relatos nacionalizadores con las modificaciones en la legislación referidas a la interculturalidad y las tensiones en su tratamiento y aplicación en la provincia de Buenos Aires. Por último, presento el plano de la "coconstrucción cotidiana" escolar, donde examino las prácticas docentes para el tratamiento crítico de la conformación del Estado nacional, la relevancia otorgada a las problemáticas de los pueblos indígenas y el diálogo con las comunidades indígenas en las escuelas.

\section{Ideas fundantes en la construcción de la nacionalidad}

En el plano de la larga duración (Rockwell, 2000) se mantiene una continuidad de los mandatos nacionalizadores que están presentes en el sistema educativo desde mediados del siglo XIX y cuya impronta fue generar una homogeneidad y la "integración" al conocimiento de la lengua, la historia y la geografía hegemónica. A continuación, presentaré brevemente algunas de las ideas fundantes sobre las cuales el Estado nacional implementó diversas políticas públicas tendientes a acreditar la unificación nacional de la actual Argentina con la finalidad de explicitar una concordancia entre estas ideas y su correlato en el sistema educativo.

\section{El Estado y la construcción la identidad nacional en perspectiva histórica}

En perspectiva histórica, la construcción de la nacionalidad comienza a constituirse con la unificación del territorio nacional en los primeros meses de 1862, cuando se estableció en la ciudad de Buenos Aires la presidencia de Mitre (1862-1868). Si bien no es el objetivo de este artículo describir las políticas de este gobierno, lo destaco por su incidencia en la construcción de un relato histórico nacional que justificó la conformación del Estado y la nacionalidad argentina.

Desde su presidencia se comenzó a "nacionalizar" a ciertos sucesos históricos y a algunos próceres que constituyeron una plataforma de narraciones históricas reconocidas como la "historia liberal". Además, fue fundador de Junta de Numismática (1893), que luego sería la Academia Nacional de la Historia (1938). Su perspectiva tuvo y aún tiene una enorme influencia en la forma en que se concibe la historia nacional y, consecuentemente, en las escuelas, la "historia mitrista" fue la corriente hegemónica durante varias décadas, y ha 
conformado el sentido común escolar que se manifiesta en los rituales basados en las efemérides patrias; sobre esto volveré más adelante.

En este sentido, en la Argentina, la instauración de la "Historia Nacional" y el nacimiento de la historiografía liberal pueden reconocerse como procesos simultáneos vinculados a la construcción del Estado. Fue Mitre quien proyectó la idea de una nación gestada en el proceso revolucionario de 1810. De esta manera, el 25 de mayo de ese año, fecha en que se instaura el primer Gobierno patrio en los territorios del Río de la Plata, se estableció como el día en que "nace la patria", dando inicio a la nacionalidad argentina, y de esta manera se consolidó en la memoria popular (de Amézola, 2008).

Paralelamente al desarrollo de la historia como disciplina científica en la Argentina, se fueron elaborando otros principios dominantes que dan basamento a las ideas fundantes del Estado nacional. Una de ellas fue la categoría de "progreso" (Briones, 2008), asociada al puerto y a la llegada de importantes contingentes de inmigrantes. Es una imagen de un país con una cabeza pequeña pero poderosa: el puerto de Buenos Aires, que sería el centro hegemónico que gobernaría un cuerpo débil, y el interior, concebido como un "desierto" habitado por poblaciones indígenas, idea que fue retomada por las sucesivas generaciones de las elites políticas. Asociado a este concepto se despliega el postulado de "civilización y barbarie": es el desierto el que contiene al "salvaje" al que había que civilizar incorporándolo al sistema nacional y al proceso productivo. Así, el proceso de construcción de la nación argentina se sostuvo en una "formación nacional de alteridad" (Segato, 2007) basada en representaciones hegemónicas, concebidas por la imaginación de las elites e incorporadas como forma de vida a partir de narrativas propagadas desde el Estado.

La nacionalidad alcanzaría la totalidad de sus potencialidades a través de la organización y la consolidación del Estado. Desde ahí se construye un ideario de nación moderna, civilizada y poderosa, que resultó hegemónico no solamente en Argentina sino en América Latina. Estos presupuestos teóricos me han permitido analizar cómo la formación de la identidad nacional es constitutiva del sistema educativo argentino y el rol preponderante que se le asigna a la enseñanza de la historia para tal fin.

\section{La enseñanza de la historia y formación la identidad nacional: apertura del debate}

En la Argentina, las narrativas oficiales de los grupos dominantes que surgieron de la propuesta mitrista y, en su versión educativa, la sarmientina, propusieron un imaginario de la población nacional a partir de la asimilación de la población indígena a un patrón civilizatorio encarnado en la sociedad blanca y europea (Neufeld y Thisted, 2007; Novaro, 2011, 2012). De esta manera, desde su surgimiento a fines del siglo XIX, la organización y consolidación del sistema educativo significó fuertes presupuestos homogeneizadores y nacionalizadores que se mantienen con matices hasta la actualidad.

A fines del siglo XIX, la enseñanza de la historia en la escuela secundaria, específicamente en los Colegios Nacionales, ${ }^{2}$ se incorpora como Historia Argentina con la reforma de 1884. Gonzalo de Amézola (2008) describe que con esta reforma se afianzó la visión mitrista y así quedó fijado el concepto de nación, junto con el panteón de héroes que tenía como máxima figura al general San Martín y los orígenes de la "nación” en la Revolución de Mayo de 1810.
2. En la constitución del sistema educativo, el nivel medio tiene distintas vertientes históricas: Colegios Nacionales, Escuelas Normales, Comerciales, de Formación Técnica e Industrial (Puiggrós, 1991; Dussel 2006; Ruiz, Molinari, Muiños, Ruiz y Schoo, 2008; Tedesco, 2009; Southwell, 2011; Acosta, 2012). 
Sin embargo, la incorporación de la asignatura Historia Argentina no trae aparejado el tratamiento de las otredades que no sean las legitimadas desde la "homogeneidad" estatal. Por lo tanto, desde fines del siglo XIX, pasando por los retoques y modificaciones superficiales de las décadas de 1940, 1950 y 1970, los diseños curriculares demostraron su enorme funcionalidad "para crear argentinos", hasta que dicha utilidad comenzó a ser cuestionada luego de la última dictadura militar a mediados de la década de 1980 (Nagy, 2013, p. 214). Para Nagy (2013), durante casi un siglo, los contenidos estuvieron dirigidos a "celebrar la patria" y a enumerar los distintos episodios y gestas patrióticas. Esta construcción de la identidad nacional se expresa en el calendario anual de las efemérides y los rituales patrios escolares vigentes en la mayor parte de los países americanos (Carretero y Kriger, 2010; Blázquez, 2012; Arata, 2014).

Sobre la enseñanza de la historia en el nivel medio, hay investigadores que presentan una especificidad en torno al tema de la identidad nacional. En este sentido, Alexander Ruíz Silva y Mario Carretero (2010) han señalado que la escuela es la instancia mediante la cual el Estado difunde e inculca a los futuros ciudadanos, de manera ininterrumpida y de generación en generación, los valores, narrativas y símbolos de la nación. Para este propósito, la enseñanza de la historia articula una serie de relatos orientados por sentimientos morales, punto focal de la enseñanza de los relatos históricos oficiales sobre el pasado de la nación (p. 40). Mencionan que la enseñanza de las historias oficiales suelen ser efectivas por despertar e infundir en las personas sentimientos de pertenencia: el orgullo de formar parte de una sociedad nacional, la seguridad de saberse incluido, al promover un comunitarismo ético radical en los connacionales.

En relación con la temática referida a los pueblos indígenas, Kriger y Carretero (2010) refieren que los relatos identitarios no promueven una percepción de la historia escolar que incorpore el conflicto, sino que más bien predomina en ellos un imperativo de pacificación. Según sus estudios, esto explicaría la ausencia de los pueblos indígenas en las representaciones estudiantiles sobre la fundación del Estado argentino. Como señalé, esta visión centralizada en el rol del Estado como garante de la nacionalidad presente en la enseñanza de la historia y en el relato histórico oficial sobre el pasado de la nación invisibiliza otros tratamientos posibles de la historia en la escuela secundaria. $\mathrm{Si}$ bien, como mencioné, hay una continuidad de las narrativas oficiales en las escuelas, hace algunos años, estas están siendo tensionadas por el tratamiento de la diferencia cultural y específicamente de la interculturalidad.

En este sentido, Sofía Thisted (2016) analiza que la diferencia cultural -que hasta no hace mucho tiempo fue considerada un obstáculo insalvable para la escolarización y para el trabajo en el aula, un atributo que era necesario disolver o remover- comienza a ser reivindicada y objeto de iniciativas en el marco de políticas educativas que las nombran y empiezan a recuperar, como plantea la perspectiva intercultural descripta por la LEN. Sin embargo, esto acontece sin que se hayan debatido los alcances del histórico mandato de homogeneización ni se hayan revisado en profundidad las formas en que tal cuestión se pone en acto (p. 16). ¿Cuál es o cuáles son los sentidos que adquiere el tratamiento de la interculturalidad en la escuela? ¿Qué plantea la legislación escolar? ¿Qué particularidades adquiere en la provincia de Buenos Aires? Para responder estas preguntas, analizaré a continuación los documentos normativos educativos actuales sobre las temáticas que son centrales en este artículo: la identidad nacional y la perspectiva intercultural. 


\section{La continuidad en la formación de la identidad nacional y la "letra muerta" de la perspectiva intercultural en la normativa escolar provincial}

Con el término "continuidad relativa", Rockwell (2000) hace referencia a esos conocimientos y prácticas que reflejan múltiples temporalidades y espacialidades pero que se mantienen relativamente. Considero que la mirada intercultural que se incorpora con la LEN en 2006 puede incluirse en este plano de análisis, ya que, como dije, tensiona las matrices sobre las que se construye la identidad nacional hegemónica.

Para esto, analizaré brevemente algunos artículos de las legislaciones vigentes y documentos complementarios que hacen referencia a estas problemáticas, partiendo de la LEN como legislación "madre", para luego analizar la Ley de Educación Provincial (2007), el Marco General de la Política Curricular (2007) y el Diseño Curricular de la asignatura Historia para tercer año de la provincia de Buenos Aires.

Sobre la identidad nacional o "ideas de nación", en el capítulo 1 de la LEN -que se refiere a los principios, derechos y garantías- en el artículo $3^{\circ}$ dice: "La educación es una prioridad nacional y se constituye en política de Estado para construir una sociedad justa, reafirmar la soberanía e identidad nacional" (Ley n.․ 26206. Ministerio de Educación, Ciencia y Tecnología). Según este fragmento, es evidente que la LEN le otorga a la educación la finalidad de reafirmar la identidad nacional, pero asociada al concepto de soberanía. Esta asociación remite a la importancia del tratamiento escolar referido a la recuperación de las Islas Malvinas, Georgias y Sandwich del Sur, una temática de historia reciente que excede a este artículo pero que adquiere relevancia en dicha normativa.

Por otro lado, el énfasis otorgado a la interculturalidad se expresa en la creación de la modalidad de Educación Intercultural Bilingüe-EIB- (capítulo XI) como transversal a la mayoría de los niveles educativos (inicial, primario y secundario). Se retoma el derecho constitucional de los pueblos indígenas según la Constitución Nacional: "recibir una educación que contribuya a preservar y fortalecer sus pautas culturales, su lengua, su cosmovisión e identidad étnica". Asimismo, "la EIB promueve un diálogo mutuamente enriquecedor de conocimientos y valores entre los pueblos indígenas y poblaciones étnicas, lingüística y culturalmente diferentes y propicia el reconocimiento y el respeto hacia tales diferencias" (Artículo 52. Ley n. ㅇ 26206. Ministerio de Educación, Ciencia y Tecnología, p. 22).

En otra jurisdicción, la Ley de Educación n.․ㅜ 13.688 de la provincia de Buenos Aires establece una educación secundaria de carácter obligatorio organizada en distintas modalidades. Entre los fines y objetivos de la política educativa del nivel secundario se destaca la función otorgada a la escuela para el fortalecimiento de la identidad nacional y la ciudadanía pero, asociado a esto, también se desprende una idea importante: el respeto a la interculturalidad y las diferencias identitarias, en este caso sin restricción a los indígenas, es decir, una interculturalidad en un sentido más amplio que la mencionada en la modalidad EIB (Artículo 28. Ley Provincial de Educación. Sistema Argentino de Información Jurídica).

Esta idea del respeto a la interculturalidad, planteada en el contexto de un reforzamiento de la identidad nacional, se retoma en los diseños curriculares 
comunes de la provincia de Buenos Aires. En la Resolución n. ${ }^{\circ}$ 3655/07, referida al Marco General de la Política Curricular en la provincia de Buenos Aires, se señala como propósito formar sujetos que reconozcan y valoren la diversidad. Desde esta perspectiva, la interculturalidad se incluye en los diseños curriculares como enfoque, estrategia y contenido. Como enfoque, porque supone un posicionamiento pedagógico desde la heterogeneidad cultural. Como estrategia, al identificar diferentes escenarios escolares, sujetos y modos de conocer y diseñar intervenciones que los pongan en diálogo. Y como contenido, al incorporar temas, nociones y saberes relacionados con las identidades culturales en los cuales los alumnos/as se reconocen (Resolución n. ${ }^{\circ}$ 3655/07. Marco General de la Política Curricular).

Es importante advertir que los marcos normativos de la LEN y de la Ley Provincial de Educación proponen desafíos para el tratamiento de la interculturalidad en la educación. Sin embargo, en los contenidos que presenta el Diseño Curricular de la asignatura Historia de $3^{\circ}$ año de la educación secundaria, referidos a la construcción del Estado-Nación, se mantiene una mirada eurocéntrica con fuerte predominio de la centralidad estatal. En la unidad 4 se focaliza en la organización de la Argentina moderna y su inserción en la economía mundial, así como en el proceso de formación del Estado. En ella se encuentran contenidos como la expansión rural capitalista, el impacto de las oleadas de inmigración, la colonización de las áreas vacías, los ciclos económicos (lanar, cereal, carne) y la concentración del poder en las elites oligárquicas. En este proceso de inserción en el modo de producción capitalista mundial de la Argentina, no se menciona la llamada Conquista al desierto de Roca (y sus justificaciones) sino solamente, como propuesta optativa, para el análisis de fuentes: "la situación social en la frontera: acciones de guerra contra los indios, la población de la campaña, contactos, intercambios" (Diseño Curricular para $3^{\circ}$ año [ES], p. 179).

Cabe preguntarnos por qué las normativas más generales referidas a la interculturalidad no se reflejan en los contenidos curriculares de tercer año de la escuela secundaria, particularmente en el abordaje de la conformación del Estado nacional, donde predomina la visión histórica centralizada en este y su inserción en el mercado mundial capitalista. Si bien no es una propuesta que enfatice la educación patriótica o nacionalista, la hegemonía centrada en el Estado en construcción excluye las problemáticas referidas al tratamiento de los pueblos indígenas. Esto parece contradictorio ya que, en los últimos años, desde el Ministerio de Educación de la Nación $(2015,2016)$ se impulsaron una serie de documentos sobre los pueblos indígenas, y desde el Instituto Nacional de Formación Docente (2016) se han desarrollados cursos sobre estas temáticas destinados a docentes (Papazián, 2018).

Por último, es importante mencionar que la provincia de Buenos Aires no ofrece propuestas específicas de EIB en su territorio. Esto la constituye como un caso paradigmático, ya que contiene la mayor cantidad de población que se reconoce como indígenas o descendientes y el mayor número de escuelas en el territorio argentino. Durante el 2007 se estableció la modalidad de EIB (Diez, Thisted y Martínez, 2015); luego, el tratamiento de la interculturalidad se implementa como programa; y en el año 2017 se desarticula totalmente (Lucas, 2018). En la actualidad, en la página de la Dirección General de Cultura y Educación hay referencias al Programa de EIB sin detallar políticas educativas claras para su implementación. 
El análisis de la legislación permitió focalizar en los marcos normativos que contextualizan las prácticas de las docentes, pero esto no supone que se apliquen acríticamente en los ámbitos escolares cotidianos, sino que, por el contrario, pueden incorporarse nuevas miradas. En el siguiente apartado presento tres instancias del trabajo de campo referidas al tratamiento de la otredad indígena que ponen en tensión las narrativas nacionalistas y amplifican las voces y demandas de las comunidades en la escuela secundaria.

\section{El tratamiento del Estado y los pueblos indígenas en la coti- dianeidad escolar}

Por último, el tercer plano, constituido por la "escala cotidiana" de las escuelas (Rockwell, 2000), permite aproximarnos a la escuela vivida y producida por quienes se encuentran diariamente ahí. Para Rockwell (2018), el vínculo entre el Estado y las clases sociales se vivencia en la realidad escolar en diversos contenidos que son variables y matizables. No solamente se observan las direcciones predominantes y unidireccionales que las teorías reproductivistas le asignaron a escuela como la institución privilegiada para la reproducción social de los grupos dominantes. En este sentido, las escuelas son un lugar privilegiado, en el cual confluyen los intereses de las clases dominantes -que utilizan al Estado como herramienta de reproducción social- con los de las clases subalternas -que ven en la educación escolar no solo un requisito para insertarse en el sistema productivo, sino la posibilidad de transformar las relaciones sociales de explotación-. Por esta razón, las relaciones sociales que se despliegan en las escuelas están en constante construcción y negociación; y se juegan intereses e historias inmediatas y apropiaciones diversas.

Este plano permite distinguir que la enseñanza de la historia escolar es abordada desde un despliegue amplio de temáticas y distintas estrategias docentes, que incluyen actividades áulicas y otras como la realización de charlas en formato de clase escolar con organizaciones de pueblos indígenas. A continuación, presentaré tres experiencias educativas en distintas escuelas donde las docentes: a) debatieron la presencia unificada del Estado en el sur bonaerense en el siglo XIX; b) vincularon los conflictos de tierras del siglo XIX con acontecimientos similares actuales; y c) amplificaron las voces y reclamos indígenas especialmente invitando a la organización Kumelén Newen Mapu a dar charlas en las escuelas.

\section{¿Dónde está el Estado? Una mirada regional del siglo XIX}

El tema de la formación del Estado argentino ha sido abordado desde distintas disciplinas sociales y variadas temáticas. Siguiendo al cientista político O. Oszlak (2012), me refiero aquí al Estado nacional y no simplemente al Estado, porque este ajuste conceptual permite describir distintas esferas que vinculan a la sociedad civil con el aparato institucional (soberanía, monopolio de autoridad y de los medios de coerción, el control de instituciones públicas y garantizar la identidad colectiva, para reforzar los sentimientos de pertenencia y solidaridad). La articulación de estas esferas es el resultado de un proceso convergente de constitución de una nación y de un sistema de dominación: relaciones de producción capitalistas y creación de símbolos y valores de pertenencia que se consolidan entre las décadas de 1860 a 1880 en la Argentina. 
3. Los nombres personales que se mencionan en este apartado (como así también los de las escuelas) son ficticios para preservar su identidad.
Con estas consideraciones previas, en este apartado retomo el abordaje de Florencia, ${ }^{3}$ profesora de Historia de tercer año, con la finalidad de analizar su perspectiva sobre la presencia del Estado (políticas públicas provinciales/ nacionales) durante las décadas anteriores a 1862, año en el que se considera la unificación nacional. En este sentido, Florencia comentó en la entrevista que uno de sus objetivos fue abordar con los alumnos cómo la fundación de Bahía Blanca había sido una de las formas en que el Gobierno provincial ejerció el poder en la región. Esto se explicitaba en el trabajo práctico que elaboró para sus alumnos, y leyó durante la entrevista:

\begin{abstract}
Hacia 1820, se trató de construir un Estado unificado. Ese fue también el caso de la provincia de Buenos Aires, hoy tu provincia. A lo largo de estas actividades queremos comprender cómo la fundación de la ciudad de Bahía Blanca fue una de las formas en que los gobiernos provinciales hicieron efectivo su poder en el interior de la provincia entre 1820 y la fecha de fundación el 11 de abril de 1828. (Fragmento del Plan de clases leído por Florencia, Bahía Blanca, 18 de mayo 2016)
\end{abstract}

Estos fragmentos permiten visualizar que la docente se refiere a un Estado en construcción, "no unificado" en tanto correspondiente al momento de la caída del poder central de Buenos Aires (1820-1823), período considerado en general en los textos historiográficos liberales como "anarquía". Pero, sobre todo, Florencia hace mención a que posteriormente, los poderes provincial y nacional tampoco controlaron los territorios del sudoeste bonaerense a pesar de haber logrado un bastión importante con la fundación de la Fortaleza Protectora Argentina en 1828. En esta idea de que Estado en formación involucra conflictos de hegemonía prevalece la lectura de que aquel se construyó subordinando a otros grupos en un proceso de expansión territorial hacia el sur provincial. Esta centralidad puede observarse también en la actividad que realizó en el aula; así quedo expresada en la carpeta de una estudiante:

\section{Un espacio sin Estado. Bahía Blanca 1820-1828 \\ Comunidades aborígenes.}

La imagen del "desierto" como construcción para nombrar lo que el poder quería. La inexistencia de lo blanco, de lo europeo que se consideraba lo civilizado, así el "desierto" aparecía como el territorio del salvaje de lo bárbaro y de la no civilización. (Notas de la carpeta de una estudiante, registro de clase, Escuela Mitre, 17 de octubre 2016).

En el plan previo de la docente y desde las notas de la estudiante (especialmente en la composición del título y subtítulo que se ven en la carpeta) se expresa la idea de un espacio sin Estado asociada al periodo previo a la fundación del fuerte de Bahía Blanca que alude a un espacio social donde éste no tenía poder. Si bien la docente presenta la dicotomía "civilización y barbarie", lo hace intentando explicitar el lugar que ocuparon los pueblos originarios en la construcción del Estado.

Es significativa la idea de que el Estado es una categoría creada históricamente y que no que no siempre se constituyó como idea inclusiva, que "no es el Estado de todos" porque no incluyó a las "comunidades aborígenes". Estas ideas que la docente despliega en sus clases ponen en tensión a las narrativas oficiales que, bajo la lupa de la historia liberal/mitrista, le otorgan al 25 de mayo de 1810 la fecha "inaugural" del Estado nacional.

Si se relaciona la propuesta de la clase de Florencia con los diseños curriculares, puede verse que, aun sin provenir de una prescripción curricular, 
algunos docentes incluyen la idea del conflicto como problemática constitutiva del Estado nacional y provincial, para relativizar la idea de un Estadonación unificado que se encuentra arraigada en el sentido común para pensar la nacionalidad.

\section{Un Estado en "tensión": los derechos territoriales de los pueblos indígenas}

En la entrevista a Araceli, profesora de Historia tercer año, ella me explicó que en sus clases suele trabajar sobre la temática de los pueblos originarios. En ellas profundiza en la "Conquista al Desierto" y recopilando noticias del diario Páginal12 y otros medios alternativos que trabajan sobre las tierras apropiadas en perspectiva histórica y actual. Se refirió específicamente a la familia Benetton y de esta manera actualizó los conflictos que transitan las comunidades indígenas en la actualidad. Esta familia de origen italiano es un caso emblemático en la Patagonia argentina porque es considerada una de las mayores poseedoras de tierras en el sur.

Araceli mencionó que utiliza estos recursos porque le resulta dificultoso encontrar materiales sobre la historia de Bahía Blanca referidos a los pueblos indígenas, y a los que accedió, los consideró "plagados de sentido común" y con una "mirada muy eurocéntrica" (Entrevista a Araceli, Bahía Blanca, 7 de abril 2016):

Araceli: La idea era que comparen el avance de la frontera de 1828 (año de la fundación del fuerte de Bahía Blanca) con la lógica de avanzar en el modelo de la estancia. Que vean que hoy con la lógica de ganancia de Benetton, o que en la lógica del cultivo de la soja (eso) continúa, sigue avanzando la frontera, incluso hoy avasallando muchos derechos que son constitucionales. Esos derechos en el 1828 no eran constitucionales, ipero hoy sí! (Entrevista a Araceli, Bahía Blanca, 7 de abril 2016)

Esta interpretación histórica que realiza Araceli respecto del momento fundacional de Bahía Blanca como un momento de violencia política y económica le permite problematizar los conflictos actuales en relación con dicho pasado, que muestran un patrón común de continuidad en la problemática del acceso a la tierra. La docente se detiene en los derechos constitucionales de los pueblos indígenas, y así establece un nexo conceptual entre un Estado agroexportador emergente a fines del siglo XIX con la venta de tierras de las comunidades indígenas y el avance de la soja en la actualidad.

Cabe aclarar que la profesora se refiere a que la actual Constitución incorporó en 1994 el reconocimiento de la preexistencia étnica y cultural de los pueblos indígenas argentinos y les garantiza el derecho a su identidad, el acceso a una educación bilingüe e intercultural y, específicamente, a la propiedad y posesión de las tierras que ocupan. Sobre el problema de la tierra, en el año 2006 se promulgó la Ley n. 26160 (Ley de Comunidades Indígenas), que declara la emergencia en materia de posesión y propiedad de las tierras ocupadas por las comunidades y se suspendieron los desalojos de los que eran víctimas estos grupos hasta ese momento.

Este paralelismo que presenta Araceli entre los acontecimientos del siglo XIX y la actualidad está claramente ausente en los diseños curriculares provinciales de tercer año, por lo que resulta un enfoque novedoso que le exige la búsqueda de recursos adicionales. Como describiré más adelante, estos conflictos actuales "entran" a las escuelas y se desarrollan en las aulas de manera que relativizan, en alguna medida, la visión uniformadora de un Estado nacional 
4. Cambiemos es el nombre de la alianza política que gobernó la Argentina entre fines del $2015 \mathrm{y}$ 2019. Nicolás Caputo fue ministro de Finanzas durante enero de 2017 y julio de 2018, y luego, presidente del Banco Central de la Argentina. Fue alejado de sus cargos por denuncias de depósitos en paraísos fiscales en el exterior y por actos de corrupción relacionados con la malversación de fondos públicos del Estado. homogeneizador y hegemónico que la escuela ha construido a lo largo del siglo XX por medio de la enseñanza de la historia. Con su propuesta, Araceli cuestiona la visión eurocéntrica de los contenidos curriculares y las fuentes históricas locales que tiene más "a mano", porque no presentan ninguna problemática vinculada a los pueblos originarios en la actualidad, a pesar de que el marco normativo de los diseños curriculares menciona reiteradamente la necesidad de prácticas interculturales.

\section{Cuestionamientos al Estado: de la "Conquista al Desierto" a Ginóbili, Santiago Maldonado y Rafael Nahuel}

En la búsqueda de recursos, Amalia, que es bibliotecaria y docente de música, y cuyo interés radica en acompañar a las demandas indígenas, se contactó con la organización indígena urbana de Bahía Blanca Kumelén Newen Mapu en el año 2015, y desde ese momento los invita a charlas en la Escuela Experimental, en la que participan profesores, profesoras y estudiantes de distintos años y materias de la escuela secundaria. Cabe aclarar que en este apartado, a diferencia de los anteriores, no se focaliza en el tratamiento áulico y en la enseñanza de la historia como contenido didáctico, sino que los relatos históricos son construidos desde las voces subalternas indígenas que recuperan distintas experiencias de las comunidades en el territorio nacional.

Durante el trabajo de campo registré cuatro charlas de la organización en esta escuela. En este artículo me referiré a una de ellas, dado que concentra la mayor cantidad de intervenciones y diálogos entre las docentes e integrantes de la organización. Por una cuestión de espacio, dejaré de lado las intervenciones de los estudiantes, ya que estas consistieron en preguntas que exceden la temática de este artículo.

En el transcurso de la charla, una de las integrantes de la organización vinculó los conflictos actuales de las comunidades originarias con los del siglo pasado, señalando que se trata en ambos casos de acciones en defensa del territorio, para evitar el desalojo de las comunidades y que los problemas territoriales atraviesan el país de norte a sur. Esta línea de continuidad histórica le permitió focalizar en un conflicto que les preocupaba demasiado: un funcionario de Cambiemos, Nicolás Caputo, ${ }^{4}$ había comprado el cerro San Martín, con el fin de desarrollar allí un complejo turístico. Esto trajo como consecuencia la tala de bosques nativos, que a su vez afectó negativamente la biodiversidad de los lugares donde viven las comunidades indígenas, que fueron las más afectadas.

Esta intervención de Quimey hacía alusión a un acontecimiento reciente, ya que en mayo de 2018 Caputo fue beneficiado con la renovación de contratos de una empresa encargada de expandir los negocios inmobiliarios en la zona del cerro San Martín (San Carlos de Bariloche, Patagonia argentina), llamado irónicamente "Cerro para los Amigos" por la vinculación que ese funcionario tenía con el Gobierno nacional, encargado de las licitaciones y los contratos empresariales.

La intervención de Quimey despertó la sorpresa de las docentes que estaban escuchando el relato, que comentaron: “¿un cerro? ¿Cómo van a comprar un cerro?". Amalia intervino en ese momento, para valorar que la organización mapuche difundiera estas situaciones que no suelen se mencionadas en los medios de comunicación, y expresó que, a su juicio, es importante que los 
estudiantes las vean y las escuchen porque "los chicos tienen una sensibilidad que nosotras no tenemos... entonces nos dan un poco de esperanza".

Quimey se refirió también al conflicto territorial con el conocido exbasquetbolista bahiense de la selección argentina Emanuel Ginóbili, quien ha sido demandado por otra comunidad localizada, en este caso, en Villa La Angostura (Neuquén, Patagonia argentina). El deportista adquirió tierras de una comunidad conocidas como "Lote 9". Estas propiedades constituyen uno de los pocos casos en que el general Roca, en nombre del Estado, le entregó tierras con "título de propiedad" a la comunidad en 1902: "la verdad es que la comunidad está peleando, está visibilizando, envían mucha información a Bahía Blanca porque saben que Ginóbili es de acá", dijo Quimey. Las tierras de la comunidad Paichil Antrilao, en la localidad de Villa La Angostura, están localizadas en una zona con alto potencial turístico: los mapuches reclaman al estado neuquino la venta de parte de las tierras en litigio al basquetbolista (Radovich, 2013; Valverde 2013).

Además de las referencias a conflictos territoriales próximos a los estudiantes (por el momento de realización de la charla, el origen del basquetbolista, la notoriedad del empresario y del político en cuestión en cada caso), durante la charla Quimey también hizo alusión a los conflictos históricos de los mapuches con el Estado. La mención a las disputas actuales de las comunidades originarias en la Argentina fue seguida de una reflexión sobre los casos de Santiago Maldonado y "Rafita" Nahuel:

Quimey: Bueno, sobre el tema de Santiago Maldonado, se dijeron muchas barbaridades, pero la gente por ahí comenzó a tomar conciencia de la cantidad de tierras que se han vendido al extranjero. ¡Es impresionante! [...] Y bueno, a Rafita Nahuel, que lo mataron por la espalda... iA la persona que lo mató creo que lo cambiaron a otro lugar y sigue trabajando como si nada! ... iEncima, Rafita Nahuel iba a llevar viandas a los integrantes de su familia que estaban haciendo el reclamo y el corte de ruta... y ahí, jlisto! lo mataron... (Registro Charla de Kumelén Newen Mapu, Escuela Experimental, 17 de mayo 2018).

El caso Santiago Maldonado fue muy relevante políticamente en Argentina, y que aconteció aproximadamente un año antes a la charla, durante el año 2017. Maldonado fue un joven que había concurrido a apoyar el reclamo de la comunidad Mapuche Pu Lof Resistencia de Cushamen, en tierras de Benetton, en la provincia de Chubut (Patagonia, Argentina). El conflicto fue reprimido violentamente por Gendarmería Nacional y Santiago desapareció durante dos meses (agosto-octubre 2017), periodo en el cual diputados y funcionarios del Gobierno nacional y algunos medios de comunicación intentaron minimizar el hecho, o culpar a la víctima (Nagy, 2018). El caso generó en importantes sectores de la población un repudio generalizado, al activar la memoria viva de la última dictadura militar argentina (1976-1982) y sus prácticas sistemáticas de "las desapariciones", lo que motivó importantes movilizaciones en todo el país. El cuerpo de Santiago fue encontrado el 17 de octubre, muerto en el río Chubut, en el mismo lugar donde se habían realizado anteriormente distintos rastrillajes.

El mismo día en que se realizó el velatorio a Maldonado (25 de noviembre de 2017), otro hecho vinculado a las comunidades indígenas adquiere relevancia nacional: el asesinato por la espalda de un joven, Rafael Nahuel, durante una represión de la Prefectura Naval en Villa Mascardi, provincia de Río Negro (Patagonia, Argentina) a la comunidad Lafken Winkul Mapu. Si bien el caso no 
adquirió la relevancia del de Maldonado, generó el repudio de los secretarios de Derechos Humanos de doce provincias, de partidos políticos de la oposición y de organismos de Derechos Humanos. También se realizaron marchas para repudiar el crimen. Rafael Nahuel tenía 22 años y hacía poco tiempo que había asumido su identidad como mapuche.

Frente a la reflexión de Quimey sobre los casos de Maldonado y Nahuel, otra docente presente recalcó la importancia de que la organización mapuche haya visitado la escuela, señalando que algunas de ellas habían tenido problemas al querer hacer referencia al caso Maldonado: “iporque a pesar de que desde arriba nos presionan, hay un montón de docentes que lo trabajamos, y es voy valioso que vengan compañeros y hermanos como ustedes para seguir poniendo las cosas en claro, jes muy importante!" (Registro Charla de Kumelén Newen Mapu, Escuela Experimental, 17 de mayo 2018).

En la charla, otra integrante de la organización Kumelén se refirió a "los cambios en los términos para nombrar a los originarios que utilizaron los distintos gobiernos", señalando que si "durante mucho tiempo se contó la historia como si los pueblos originarios fueran salvajes, ahora el término cambió y se los llama "terroristas", porque tiene mucho más marketing la palabra terrorista", señalando que de esta manera se "deshumaniza", entonces "los pueblos originarios ya no son salvajes, son terroristas" y así se justifica la quita de tierras (Registro Charla de Kumelén Newen Mapu, Escuela Experimental, 17 de mayo 2018).

Esta charla efectuada en la escuela Experimental permitió considerar cómo en las instituciones emerge la problematización explícita del paradigma civilizatorio que subyace en las formas hegemónicas de transmitir los acontecimientos ligados a la fundación de Bahía Blanca, dado que así se formula una visión histórica y actual de los pueblos indígenas desde su propia perspectiva. Ante un auditorio de jóvenes que escucharon con atención la pausada voz de las referentes mapuche, se abordaron distintas temáticas referidas a los pueblos indígenas que no habían estado presentes sino muy tangencialmente en las clases, y estaban totalmente ausentes en la propuesta de los diseños curriculares.

\section{A modo de cierre}

En este artículo presenté el trabajo de campo etnográfico en distintas escuelas secundarias del sur de la provincia de Buenos Aires, donde focalicé en el tratamiento de diversas problemáticas referidas a la formación del Estado nacional y los pueblos originarios. De esta manera analicé algunas tensiones que se presentan en la enseñanza de la historia y el mandato nacionalizante de la escuela, legitimada históricamente en sus funciones de fortalecimiento de la identidad nacional.

En el plano de la "larga duración" señalé que hay una continuidad de los mandatos nacionalistas, presentes en la normativa escolar, en los diseños curriculares y en las prácticas y rituales de las efemérides. De esta manera describí las ideas fundantes de la identidad nacional en la Argentina impulsadas por las elites dominantes, de acuerdo con las cuales los pueblos indígenas debían ser "asimilados" al Estado nacional, y en qué medida se reflejaron estas ideas en la currícula escolar. Como he descripto, estos mandatos se han mantenido con una "continuidad relativa", pero se reactualizan con el tratamiento de la diversidad cultural luego de la última dictadura militar y en particular con la perspectiva intercultural de la LEN. 
La perspectiva intercultural presente en los marcos legislativos permitió cuestionar el paradigma liberal en la enseñanza de la historia, sin embargo, en el diseño curricular de tercer año de la escuela secundaria en la provincia de Buenos Aires se invisibiliza a los pueblos originarios y los procesos de disputas territoriales en la conformación del Estado. A su vez, la provincia no cuenta con escuelas de EIB, y la implementación de una política educativa intercultural aún está en suspenso. De esta manera, son la docentes las que proponen de maneras muy diversas el tratamiento de las problemáticas históricas y actuales que involucran a los pueblos indígenas y establecen prácticas tendientes a fortalecer la perspectiva intercultural que se desprende de la normativa del sistema educativo.

El trabajo de campo permitió analizar la heterogeneidad de las prácticas docentes en la cotidianeidad escolar para debatir la visión hegemónica del Estado en un área de frontera en el siglo XIX y tensionar su rol en la actualidad, al abordar temas como la apropiación de tierras indígenas por parte de los terratenientes extranjeros. La presencia de la organización indígena amplió el cuestionamiento al Estado al tratar los conflictos territoriales, como son los casos Ginóbili y la violencia estatal en la desaparición de Santiago Maldonado y el asesinato de Rafael Nahuel. El tratamiento de estas temáticas puso de relieve la violación a los derechos humanos que vivencian las comunidades indígenas y la responsabilidad estatal.

\section{Agradecimientos}

Este artículo reactualiza una parte de la investigaciones realizadas durante el doctorado. En primer lugar quiero agradecer a las docentes y estudiantes de diversas escuelas secundarias que me permitieron vivenciar su cotidianeidad escolar. A las representantes de la organización Kumelén Nehuen Mapu, a mi directora la Dra. Ana Padawer ya la Dra. Alejandra Pupio que fue mi codirectora. Por último a lxs evaluadorxs de este artículo y a las coordinadoras del dossier.

\section{Biografia}

Doctor en Antropología (FFyL. UBA). Diplomado Superior en Antropología Social y Política (FLACSO-Argentina). Profesor y Licenciado en Historia (UNS). Se especializa en el campo de la Antropología y Educación. Es profesor e investigador en el Dpto. Humanidades (UNS). 


\section{Q Referencias bibliográficas}

"Acosta, F. (2012). La escuela secundaria argentina en perspectiva histórica y comparada: modelos institucionales y desgranamiento durante el siglo XX. Cadernos de História da Educação, 11(1), 131-144.

"Alioto, S. L. (2011). Indios y ganado en la frontera. La ruta de río Negro (1750-1830). Departamento de Humanidades. Rosario: Protohistoria.

» Arata, N. (2014). Efemérides: una oportunidad para pensar la vida común. Ciudad Autónoma de Buenos Aires: Mandioca.

» Blázquez, G. (2012). Los actos escolares. El discurso nacionalizante en la vida escolar. Buenos Aires: Miño y Dávila.

"Briones, C. (2008). Formaciones de alteridad: contextos globales, procesos nacionales y provinciales. En C. Briones (Comp.). Cartografías argentinas: políticas indigenistas y formaciones provinciales de alteridad (pp. 9-36). Buenos Aires: Antropofagia.

»Carretero, M. y Kriger, M. (2010). Enseñanza de la historia e identidad nacional a través de las efemérides escolares. En M. Carretero y J. A. Castorina. La construcción del conocimiento histórico: enseñanza, narración e identidades (pp. 81-98). Buenos Aires: Paidós.

"Cernadas, M. N., Bracamonte L., y Agesta, M. N. (2016). Bahía Blanca de la segunda fundación a la sociedad de masas (1880-1943). En Escenarios de la sociabilidad en el sudoeste bonaerense durante la primera mitad del siglo XX (pp. 15-45). Bahía Blanca: Ediuns.

»De Amézola, G. (2008). Esquizohistoria. La Historia que se enseña en la escuela, la que preocupa a los historiadores y una renovación posible de la historia escolar. Buenos Aires: Libros del Zorzal.

»Delrio, W. D. (2010). Memorias de expropiación: sometimiento e incorporación indígena en la Patagonia: 1872-1943. Bernal: Universidad Nacional de Quilmes.

»Delrio, W. D. (2011). Genocidio como categoría analítica: memoria social y marcos alternativos. En Corpus. Archivos virtuales de la alteridad americana, 1(2). Recuperado de http://ppct.caicyt.gov.ar/index.php/corpus

"Delrio, W. D. (2015). Caciques, concentraciones y reclutamientos. Campañas de conquista e imposición estatal en el norte de la Patagonia. TEFROS, 13(1), 149-181.

»Diez, M. L., Thisted, S., y Martínez, M. E. (2015). Educación intercultural como política pública: el análisis de la experiencia de la provincia de Buenos Aires. Boletín de Antropología y Educación, 9, 163-168.

» Diez, M. L., Enriz, N., García Palacios, M., Hecht, A. C., Martínez, L., Novaro, G. y Padawer A. (2016). Escuela, campañas militares y genocidio indígena. Reflexiones a partir de los comentarios del Ministro de Educación y Deportes de la Nación. Boletín de Antropología y Educación, 10, 61-63.

»Dussel, I. (2006). Currículum y conocimiento en la escuela media argentina. Anales de la educación común. Tercer siglo, 4, 95-105.

"Heredia Chaz, E. (2018). La tercera fundación de Bahía Blanca: Ia ciudad en la transformación neoliberal. Bahía Blanca: Ediuns.

" Kriger, M. y Carretero, M. (2010). Historia, identidad y proyecto. Narraciones de los jóvenes sobre la independencia de la nación. En M. Carretero y J. A. Castorina. La construcción del conocimiento histórico: enseñanza, narración e identidades (pp. 81- 98). Buenos Aires: Paidós. 
"Lenton, D. (2010). Presentación del debate: Genocidio y política indigenista. Debates sobre la potencia explicativa de una categoría polémica. Corpus. Archivos virtuales de la alteridad americana, 1(2). Recuperado de http://ppct.caicyt.gov.ar/index.php/corpus

"Lenton, D. (2014). Políticas de estado y pueblos originarios en Argentina. Apuntes en torno a la aplicabilidad del concepto de genocidio en la historia de las relaciones entre el estado argentino y los pueblos originarios. En J. L. Lanata (Comp.). Prácticas genocidas y violencia estatal en perspectivas transdiciplinar (pp. 32-51). San Carlos de Bariloche: IIDyPCa-CONICET. Recuperado de http://biblioteca.clacso.edu.ar/Argentina/iidypcaunrn/20171115054357/pdf_109.pdf

"Lucas, M. (2018). Acciones educativas interculturales en la Provincia de Buenos Aires (Argentina). Polifonías Revista de Educación, 12, 81-106.

» Nagy, M. (2013). Una educación para el desierto argentino. Los pueblos indígenas en los planes de estudio y en los textos escolares actuales. Espacios en Blanco. Revista de Educación, 23, 187-223.

"Nagy, M. (2018) Un relato perdurable: la realización simbólica en el genocidio de los pueblos originarios en Argentina. Revista de Estudios sobre Genocidio, 9(13), 63-79.

"Navarro Floria, P. (2002). El desierto y la cuestión del territorio en el discurso político argentino sobre la frontera. Revista Complutense de Historia de América, 28, 139-168.

" Neufeld, M. R. y Thisted, J. A. (2007). El “crisol de razas" hecho trizas: ciudadanía, exclusión y sufrimiento. En De eso no se habla: los usos de la diversidad sociocultural en la escuela (pp. 23-56). Buenos Aires: Eudeba.

》 Novaro, G. (2011). Niños y escuelas. Saberes en tensión. En G. Batallán y M. R. Neufeld (Coords.). Discusiones sobre infancia y adolescencia: niños y jóvenes dentro y fuera de la escuela (pp. 179-198). Buenos Aires: Biblos.

"Novaro, G. (2012). Niños migrantes en Argentina. Nacionalismo escolar, derechos educativos y experiencias de alteridad. Revista Mexicana de Investigación Educativa, 17(53), 459-483.

" Oszlak, O. (2012). La formación del Estado argentino: orden, progreso y organización nacional. Buenos Aires: Ariel.

» Papazián, A. (2018). El Programa Nuestra Escuela y el genocidio indígena. Ponencia IV Encuentro hacia una pedagogía emancipadora en nuestra América. Recuperado de https://pedagogiaemancipatoria.files.wordpress.com/2018/og/papazian.pdf

»Puiggrós, A. (Dir.). (1991). Sociedad civil y Estado en los orígenes del sistema educativo argentino. Buenos Aires: Galerna.

"Radovich, J. C. (2013). Los mapuches y el Estado neuquino: algunas características de la política indígena. Runa, 34(1), 13-29. Recuperado de http://revistascientificas.filo.uba.ar/ index.php/runa/article/view/560

» Rockwell, E. (2000). Tres planos para el estudio de las culturas escolares: el desarrollo humano desde una perspectiva histórico-cultural. Interações, 9(5), 11-25.

» Rockwell, E. (2018). Escuela y clases subalternas. En N. Arata, J. C. Escalante y A. Padawer (Comps.). Vivir entre escuelas: relatos y presencias. Antología esencial (pp. 57-76). Ciudad Autónoma de Buenos Aires: CLACSO.

» Ruiz Silva, A. y Carretero, M. (2010). Ética, narración y aprendizaje de la historia nacional. En M. Carretero y J. A. Castorina. La construcción del conocimiento histórico: enseñanza, narración e identidades (pp. 31-54). Buenos Aires: Paidós.

" Ruiz, G., Molinari, A., Muiños, C., Ruiz, M. y Schoo, S. (2008). La estructura académica del sistema educativo analizada a partir de los contenidos de enseñanza. La educación secundaria durante las primeras décadas del siglo XX. Anuario de Investigaciones, 15, 265-276. 
»Segato, R. L. (2007). Introducción: políticas de la identidad, diferencia y formaciones nacionales de alteridad. En La Nación y sus otros: razas, etnicidad y diversidad religiosa (pp. 15-36). Buenos Aires: Prometeo.

»Southwell, M. (2011). La educación secundaria en Argentina. Notas sobre la historia de un formato. En G. Tiramonti (Dir.). Variaciones sobre la forma escolar. Límites y posibilidades para la escuela media (pp. 35-70). Buenos Aires: FLACSO; HomoSapiens.

» Tedesco, J. C. (2009). Educación y Sociedad en Argentina (1880-1945). Buenos Aires: Solar.

» Thisted, S. (2016). Culturas magisteriales y educación intercultural en Argentina. Construcción histórica de posiciones docentes ante las diferencias y las desigualdades. En Actas XI Seminario Internacional de la Red Estrado. Movimientos Pedagógicos y Trabajo Docente en tiempos de estandarización (pp. 1-19). Recuperado de http://redeestrado.org/xi_seminario/pdfs/eixo8/306.pdf

»Valverde, S. (2013). De la invisibilización a la construcción como sujetos sociales: el pueblo indígena Mapuche y sus movimientos en Patagonia, Argentina. Anuário Antropológico, 38. Recuperado de https://journals.openedition.org/aa/414?lang=en

»Villar, D. y Jiménez, J. F. (2004). Como buche de ñandú. Negocios en la frontera: pulperos, militares, hacendados e indígenas en Bahía Blanca, hacia mediados del siglo XIX. En D. Villar y S. Ratto (Eds.). Comercio, ganado y tierras en la frontera de Bahía Blanca (1850-1870) (pp. 7-26). Bahía Blanca: Centro de Documentación Patagónica, Departamento de Humanidades. Universidad Nacional del Sur.

» Villar, D., Jiménez, J. F, Ratto, S. (1998). Relaciones Inter-étnicas en el Sur Bonaerense 18101830. Bahía Blanca: Departamento de Humanidades, Universidad Nacional Del Sur. Instituto de Estudios Histórico-Sociales, Universidad Nacional del Centro de la Provincia de Buenos Aires.

\section{Otras fuentes consultadas}

" Cámara de Diputados de la provincia de Buenos Aires. (27 de junio de 2007). Ley de Educación Provincial. [Ley n. $\stackrel{0}{13688}$ ]. Recuperado de http://abc.gov.ar/primaria/sites/ default/files/documentos/ley-13688-07.pdf

»Conflicto Mapuche: Juntos por el Cambio acusó al Estado de perder la soberanía sobre Villa Mascardi, (31 de marzo 2021). Infobae. Recuperado de https://www.infobae.com/ politica/2021/03/31/conflicto-mapuche-juntos-por-el-cambio-acuso-al-estado-de-perder-la-soberania-sobre-villa-mascardi/

»Dirección General de Cultura y Educación de la provincia de Buenos Aires. Resolución n. ${ }^{\circ}$ 3655. Marco General de la Política curricular. 2007. Recuperado de http://servicios. abc.gov.ar/lainstitucion/organismos/consejogeneral/disenioscurriculares/documentosdescarga/marcogeneral.pdf

»Dirección General de Cultura y Educación de la Provincia de Buenos Aires. 2008. Diseño curricular para la educación secundaria $3^{\circ}$ año.

»El conflicto mapuche. (6 de marzo 2021). La Nación. Recuperado de https://www.lanacion.com.ar/editoriales/el-conflicto-mapuche-nido6o32021/

» Ministerio de Educación, Ciencia y Tecnología. (14 de diciembre de 2006). Ley de Educación Nacional [Ley n. ํㅜㄹㅡ.

» Sistema Argentino de Información Jurídica. Ley Provincial de Educación. Recuperado de https://www.abc.gob.ar/rrhh/sites/default/files/ley-provincial-de-educacionba_13.688_o.pdf 